\title{
Lech Murawski
}

http://dx.doi.org/10.21278/brod67402

ISSN 0007-215X

eISSN 1845-5859

\section{THERMAL DISPLACEMENT OF CRANKSHAFT AXIS OF SLOW-SPEED MARINE ENGINE}

UDC 629.5(05):621.436

Original scientific paper

\begin{abstract}
Summary
The paper presents analysis of displacement of a crankshaft axis caused by temperature of marine, slow-speed main engine. Information of thermal displacement of a power transmission system axis is significant during a shaft line alignment and a crankshaft springing analysis. Warmed-up main engine is a source of deformations of an engine body as well as a ship hull in the area of an engine room and hence axis of a crankshaft and a shaftline. Engines' producers recommend the model of parallel displacement of the crankshaft axis under the influence of an engine heat. The model gives us the value (one number!) of the crankshaft axis displacement in the hot propulsion system's condition. This model may be too simple in some cases. Presented numerical analyses are based on temperature measurements of the main engine body and the ship hull during a sea voyage. The paper presents computations of MAN B\&W K98MC type engine (power: $40000 \mathrm{~kW}$, revolutions: $94 \mathrm{rpm}$ ) mounted on 4500 TEU container ship (length: $290 \mathrm{~m}$ ). Propulsion system is working in nominal, steady-state conditions; it is the basic assumption during the analyses. Numerical analyses were preformed with usage of Nastran software based on Finite Element Method. The FEM model of the engine body comprised over 800 thousand degree of freedom. Stiffness of the ship hull (mainly double bottom) with the foundation was modelled by a simple cuboid. Material properties of that cuboid were determined on the base of separately performed calculations.
\end{abstract}

Key words: $\quad$ temperature deformation; marine propulsion system; shaftline alignment; crankshaft springing; slow-speed main engine

\section{Introduction}

Proper shaftline alignment is one of the most important procedures during marine propulsion system designing, installation and exploitation. The axis of journal bearings of shaftline should be displaced (mainly in vertical direction) to the proper position $[1,2,3]$. Usually, the crankshaft axis is a baseline for shaftline alignment. Even bearings loads and proper interaction between a shaftline and a crankshaft is the aim of this procedure. Measurements of crankshaft springing give information about the proper engine foundation as well as the proper loads coming from shaftline. During the shaftline alignment and crankshaft springing analyses, knowledge of the thermal displacement of the crankshaft axis is essential. 
Engines' producers proposed the model of crankshaft axis thermal displacement but it is very simple. They recommend the model of parallel displacement of a crankshaft axis under the influence of engine heat. Such a model give us one number - a value of crankshaft displacement between cold and hot propulsion system (in steady state condition), different for each type of engine. Sometimes (but not always!), the displacement value is depended on the temperature difference between not running and running propulsion system. In such a case the model might be too simple. Couplings between thermal (with influence of electromagnetic field) and mechanical loads of a marine propulsion system are very complicated and cannot be omitted during analyses of a main engine mounting [4]. Practically, a relatively simple model of the thermal-mechanical coupling is sufficient: the engine temperature is a source of the body, main bearings and crankshaft displacement; and so the displacements are a source of additional mechanical loads of propulsion system's bearings. For example, problems with shaftline alignment and crankshaft springing are befalling especially for high powered engine mounted on optimised (light - with elastic hull) ships $[5,6]$.

The aim of the presented analyses has been evaluation of displacements of the crankshaft axis under a steady-state thermal load [7,8]. Up to now in the shaft line alignment typical methodology, an interaction of the crankshaft and the shaft line was considered in a simplified way. The crankshaft was modelled as a linear system of cylindrical beam elements, while its displacements due to working temperature and its foundation stiffness were evaluated based on a simple data supplied by the producer, which did not address the type of the ship on which the engine is mounted [2]. Presented research goal has been a better representation of the boundary conditions of the marine power transmission system. It is especially important for the high power propulsion systems, as in the literature there may be found numerous examples of the damage of the first three (counting from the driving end) main bearings of the main engine [9, 10]. One of the causes might be the imprecise mathematical model of a crankshaft proposed for the shaft line alignment analysis.

Marine power transmission systems are modelled as isolated from ship hull and engine body $[11,12,13,14]$. There are several reasons for this methodology. Difficulties with the proper oil film calculation (Reynolds's equation) and the need for a detailed crankshaft, engine body and ship hull FEM model are ones of the most important. That is why I apply this methodology in my research. Within the research there have been carried out a number of analyses of MAN B\&W K98MC engine mounted on a container ship ( 4500 TEU). The computation of the engine's body deformation due to the gravity and its natural eigenvectors has been performed as well as the analysis of its thermal deformation in nominal work conditions. The thermal analysis requires an accurate temperature distribution on the engine's body. Wide temperature measurements on the ship and her main engine supplied the appropriate data. The temperature measurements were performed during a ship sea voyage. The main data of the analysed ship are as follows: the total length - $292 \mathrm{~m}$, the width - $32 \mathrm{~m}$, the maximal draught - $13 \mathrm{~m}$, the maximal caring capacity - 58000 ton, the ship's speed with $90 \%$ MCR 24 knots. The main data of the analysed main engine are as follows: the power $-40000 \mathrm{~kW}$, the nominal revolutions - $94 \mathrm{rpm}$, the crankshaft journal diameter - 1062/400 mm, the crankshaft pin diameter $-1062 / 531 \mathrm{~mm}$. The main data of the analysed power transmission system are as follows: the intermediate shaft diameter $-735 \mathrm{~mm}$, the propeller shaft diameter $-845 \mathrm{~mm}$, the propeller diameter $-8.20 \mathrm{~m}$, number of blades -5 , the propeller mass $-72200 \mathrm{~kg}$.

\section{Model verification}

All analyses were performed on the base of Finite Element Method. The commercial software: Patran - Nastran was used for modelling and numerical calculations. The FE model of the B\&W K98MC main engine's body has been presented in Fig. 1. Fig. 2 presents a part of the model with details of the engine's main bearing foundation. The foundation of crankshaft 
in the main bearings is the most important region in the presented type of analysis. FEM model of main bearings is realised by 3-D solid elements (8-nodes), the rest part of engine body is modelled by 4-node plate elements. The whole FEM model of the engine' body has over 812 thousands degrees of freedom and over 170 thousands elements. Engine model is 8 times (!) greater than model of the ship hull (see Fig. 3). It is the main reason for separate calculations of the engine temperature deformations and the ship hull stiffness.

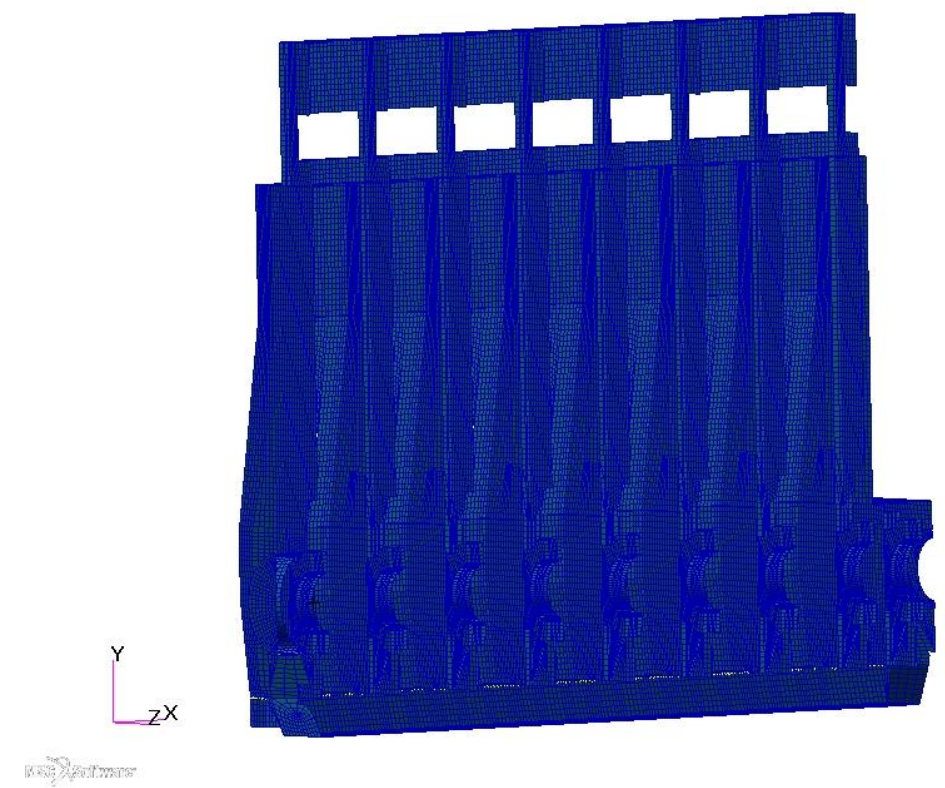

Fig. 1. Model of the main engine body

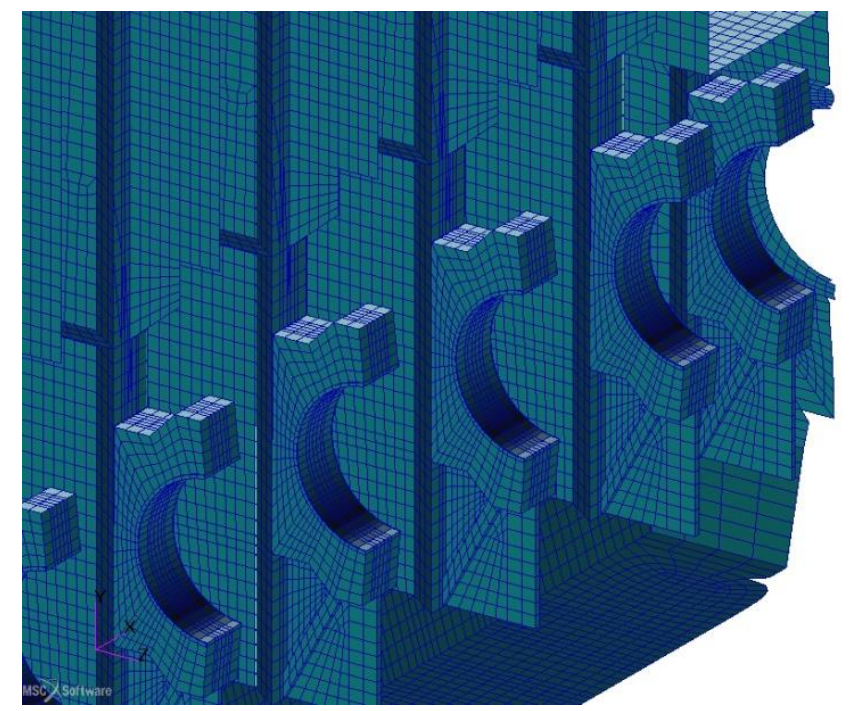

Fig. 2. Details of the engine's main bearing foundation

The detailed model of the engine body has to be analysed as separated from the ship hull. Three types of engine foundation model (boundary conditions) were analysed. First one is classical - known from literature: foundation arms are completely blocked (fixed deformation). In the second way the ship hull stiffness was modelled by beam elements. This method does not take into account couplings between supporting points of the ship hull (the ship hull is treated as a continuous beam). In the third method the foundation arms are modelled by continuous cuboid (with the cross section $0.468 \times 0.5 \mathrm{~m}$ ) with special material properties. On the base of the separate analyses, the stiffness of the ship hull in the engine room area (with the 
fundaments) was estimated and its value is equal to $1.1 \times 10^{9} \mathrm{~N} / \mathrm{m}$. FEM model of the container ship for those analyses is presented in Fig. 3. Area of all propulsion systems bearings' foundation was distinguished and loaded by unitary pressure [15]. Displacements of the bearings give me the value of the ship hull local stiffness. During separate calculations, the properties of the vicarious cuboid were determined in the way that the local stiffness of the cuboid was equal to the local stiffness of the ship hull with the engine foundation. The Young's modulus was determined as $\mathrm{E}=9.2 \times 10^{9} \mathrm{~Pa}$.

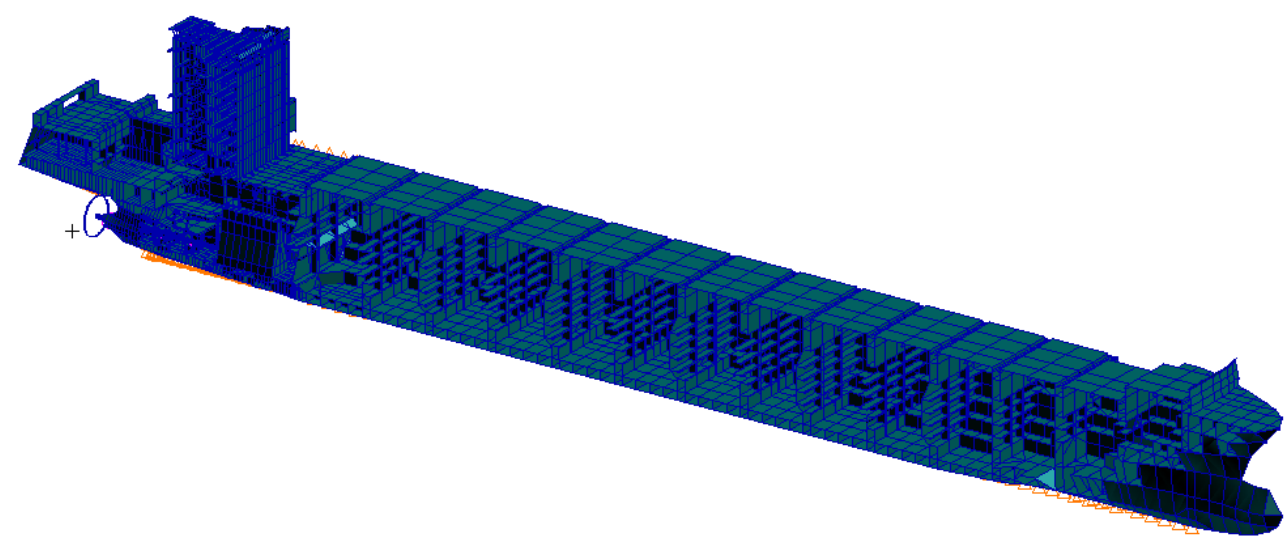

Fig. 3. FEM model of 4500 TEU container ship

The model of the engine body was verified by eigenvalue vectors (natural vibrations) determinations. The main target of that kind of analysis is model coherence checking. In my opinion, each FEM model (even made up for static type analysis) should be checked by natural modes analysis. It was assumed that dynamic characteristics of engine main bearings should be performed in the range of $0-30 \mathrm{~Hz}$ because the main force harmonic component of the engine is equal to $10.97 \mathrm{~Hz}$ ( $94 \mathrm{rpm}, 7$ cylinders) and the propeller's is equal to $7.83 \mathrm{~Hz}$ ( 5 blades). Examples for the most interesting natural modes of the engine body with the vicarious model of the ship hull are presented in Fig. 4-6. The names of the shape modes are commonly used by marine engine producers. H-mode describes transverse vibrations of the engine body (Fig. 4). $\mathrm{X}$-mode describes torsional vibrations of the engine body (Fig. 5). The obtained frequencies values are confronted with my own experience in measurements and calculations and are assessed as correct (up to an order of magnitude).

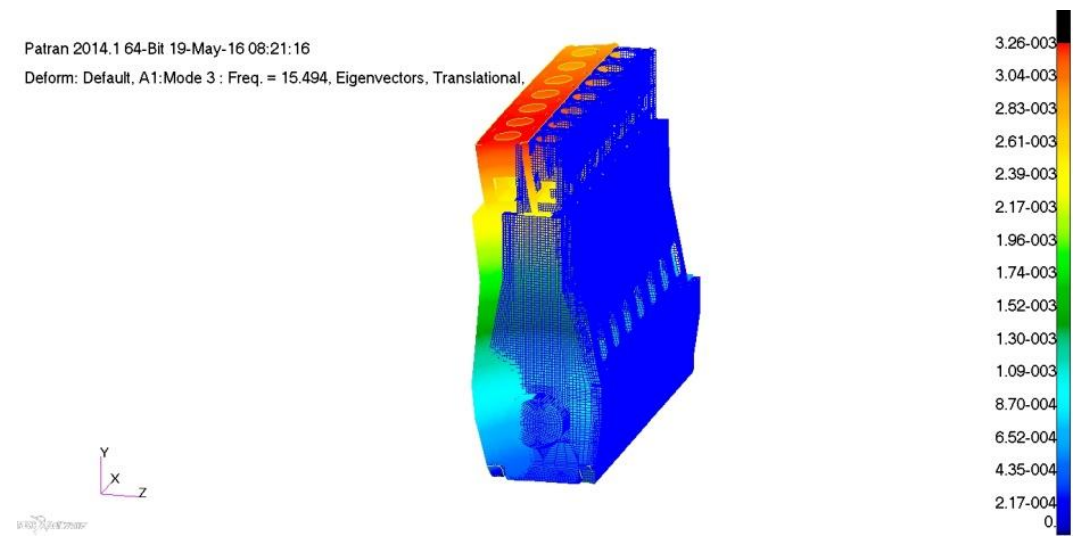

Fig. 4. H-mode $(15.5 \mathrm{~Hz})$ of engine body natural vibrations 

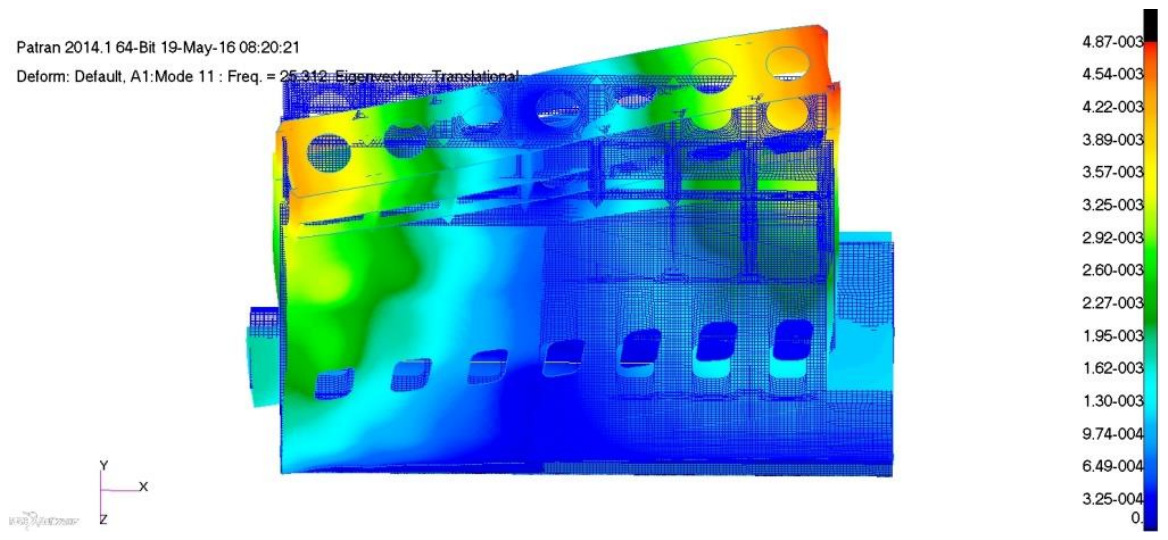

Fig. 5. X-mode $(25.3 \mathrm{~Hz})$ of engine body natural vibrations
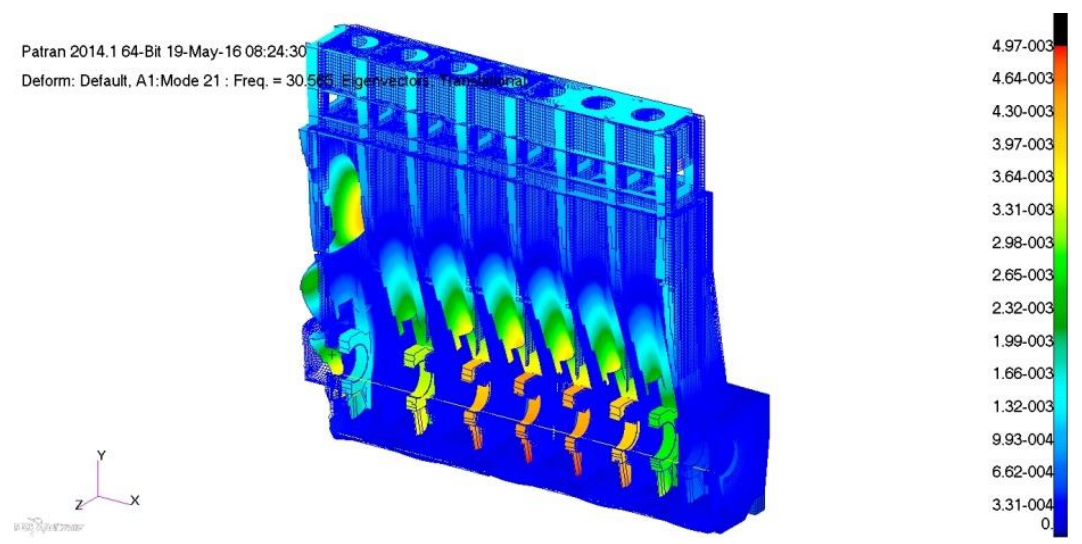

Fig. 6. Mode $(30.6 \mathrm{~Hz})$ of main bearings foundation natural vibrations

Values of natural frequencies for each type of boundary conditions (the modelling method of the ship hull and the engine foundation) were compared. While the boundary conditions have not very important influence on natural frequencies of the main bearings foundations, these conditions affect the global engine eigenvalues very much. The modelling method of the boundary conditions (the ship hull stiffness with the engine foundation) is essential during engine body analyses. Fixed nodes in the foundation arms area give us too stiff model but hull stiffness modelled by beams gives us too elastic model (because of not taking into account couplings between hull areas). The values of calculated natural vibration frequencies are shown in table 1. Model with cuboid foundation is the best and it is consistent with author's experience (comparison with measurements onboard of typical main engine body natural frequencies). During further calculations cuboid model will be analysed. On the base of natural vibrations analyses it may be observed that stiffness of the engine body (especially of the main bearings foundations) is high. It is much higher than primary excitation frequencies of propulsion system. Therefore, the dynamic stiffness of the engine bearings is not much different to the static stiffness. 
Table 1 Natural vibration frequencies of the main engine body

\begin{tabular}{|c|c|c|c|}
\hline $\begin{array}{c}\text { Type of } \\
\text { mode }\end{array}$ & $\begin{array}{c}\text { The ship hull stiffness } \\
\text { not modelled (fixed } \\
\text { displacement) }\end{array}$ & $\begin{array}{c}\text { The ship hull stiffness } \\
\text { modelled by beam } \\
\text { elements }\end{array}$ & $\begin{array}{c}\text { The ship hull stiffness } \\
\text { modelled by } \\
\text { continuous cuboid }\end{array}$ \\
\hline $\mathrm{H}$ & $22.6 \mathrm{~Hz}$ & $12.4 \mathrm{~Hz}$ & $15.5 \mathrm{~Hz}$ \\
\hline $\mathrm{X}$ & $31.3 \mathrm{~Hz}$ & $24.1 \mathrm{~Hz}$ & $25.3 \mathrm{~Hz}$ \\
\hline $\begin{array}{c}\text { Mode of } \\
\text { main } \\
\text { bearings } \\
\text { foundation }\end{array}$ & $31.4 \mathrm{~Hz}$ & $29.1 \mathrm{~Hz}$ & $30.6 \mathrm{~Hz}$ \\
\hline
\end{tabular}

\section{Temperature distribution of engine body}

Before the start of the thermal deformation analysis of the engine body it is necessary to determine the engine temperature distribution. The temperature map has been created on the basis of the measurements carried out on a marine main engine during sea trials. The temperature determination on the base of measurements is much more accurate in comparison to calculation analysis of heat transfer. Calculation has to be based on several values which are difficult for determination, e.g. the power of heat source, the temperatures of oil and cooling water, and the coefficients of heat transfer. The engine load was under stable parameters of nominal working condition. The meter used for measurement was pyrometer made by AlfaTech type Rytek MT 4. The temperature was measured in 60 points located around whole engine body. Ten points were located regularly around the cylinder heads; twenty points were located regularly on each lateral side of the engine body and ten points were located regularly on the fore and aft sides of the engine body. There is a big difference between cylinder heads and other part of engine body. The temperature distribution was estimated (with using linear interpolation between measured points) and included in the numerical model. The temperature distribution of cylinder heads and other part of the engine body is presented in Fig. 7 and Fig. 8 .

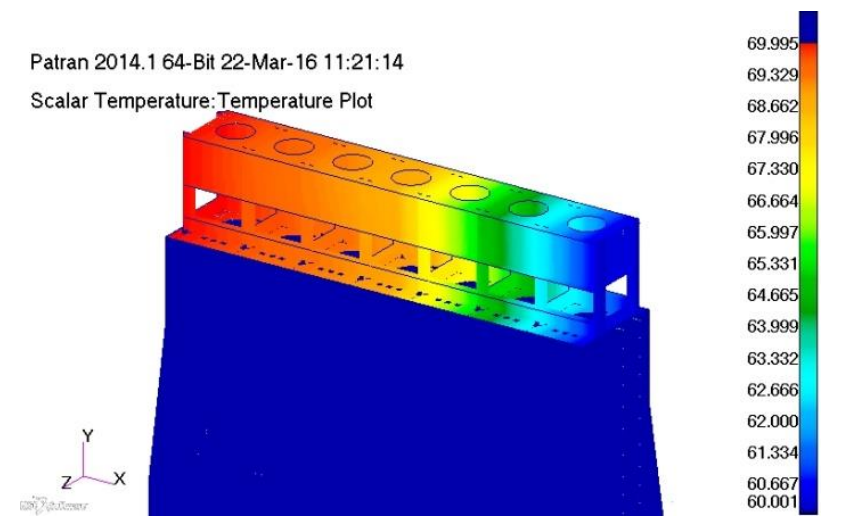

Fig. 7. Temperature distribution measured on cylinder heads 


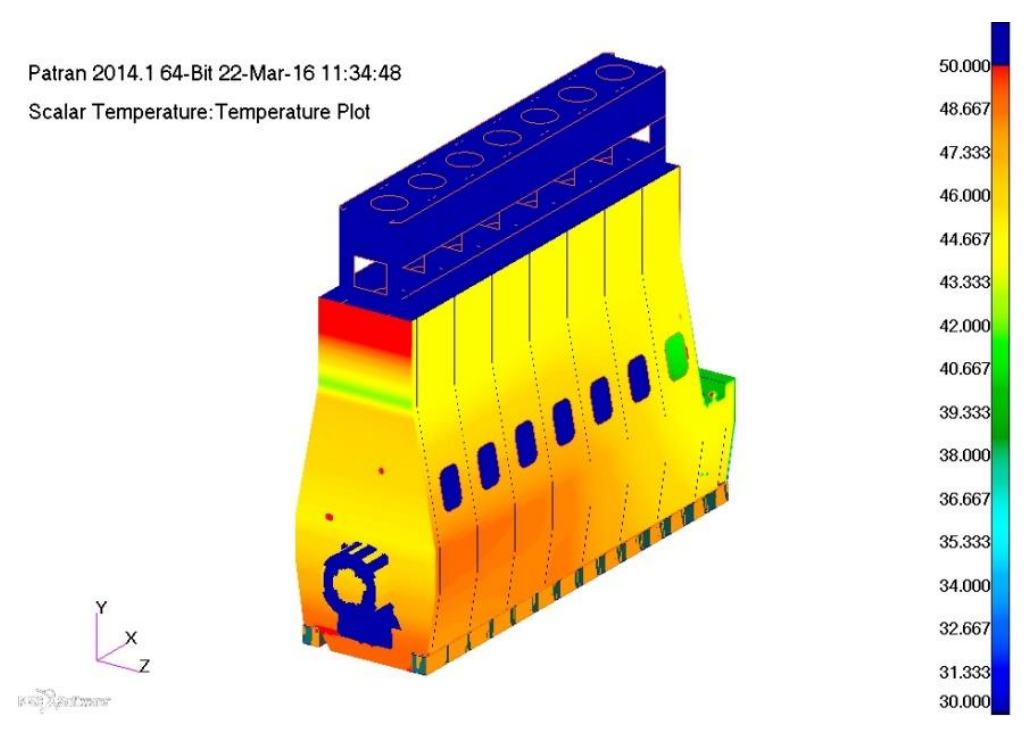

Fig. 8. Temperature distribution measured on engine body

Of course, the temperature of the inner parts of engine body had to be estimated. The estimation was performed on the base of lubricating oil temperature measured at the inlet and outlet as well as on the base of cooling water inlet and outlet and temperature of exhaust gases. The temperature distribution of the inner part of the engine body is presented in Fig. 9.

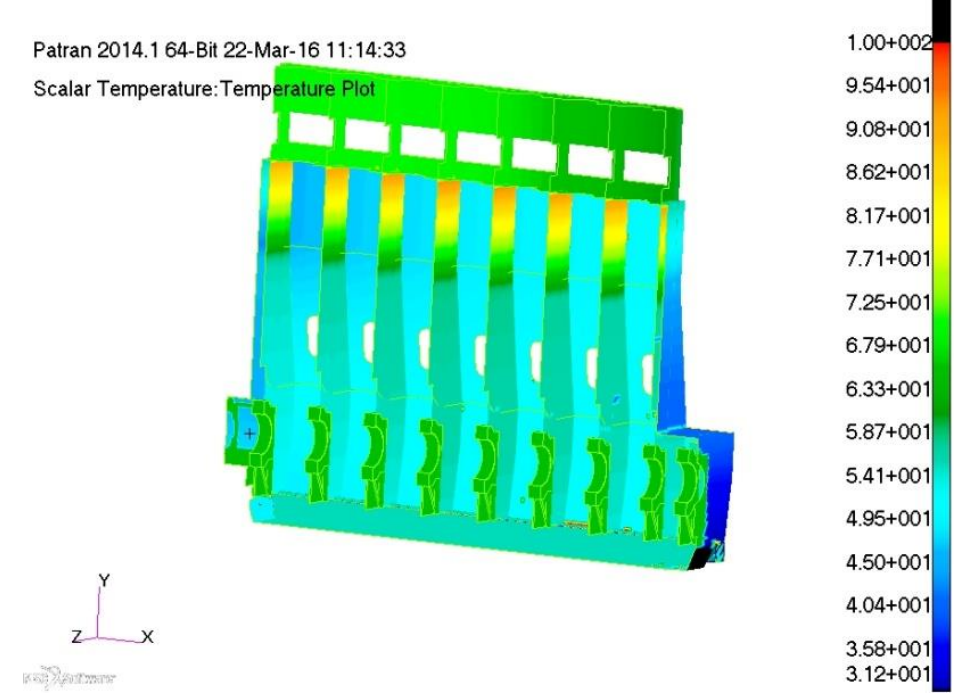

Fig. 9. Temperature distribution estimated for inner part of engine body

\section{Thermal analysis of engine body deformation}

The coefficient of thermal expansion of the engine's body has been assumed as $\alpha=1.6 \times 10^{-}$ 5. The temperature distribution has been applied to the engine's body analogous to the one obtained from the measurement (see Fig. 7-9). A thermal deformation of the main engine's body is presented in Fig. 10. On this and all next figures the SI standard unit is compulsory (e.g. $\mathrm{m}, \mathrm{Pa}$ ). From a point of view of the propulsion system and the main engine - shaft line cooperation, the most important are the displacements of the main bearings of the engine. The thermal displacements of the main bearings foundation in engine body is presented in Fig. 11. The values of the displacements are presented in table 2 . The bearing numbering begins from the crankshaft free-end (opposite to shaft line). A diagram of the vertical thermal displacement of the crankshaft axis is presented in Fig. 12. The yellow circles show the places of the main bearings. According to the producer's information: "all main engine bearings are placed in hot 
condition higher than in cold condition". Total vertical thermal displacement of the engine bearings in hot condition, when comparing with cold condition, is equal to: $h_{e}=0.37 \mathrm{~mm}$ according to MAN B\&W drawing No. 0793023-4, when the engine temperature is raised from cold $\left(20^{\circ} \mathrm{C}\right)$ to normal running temperature $\left(55^{\circ} \mathrm{C}\right)$.

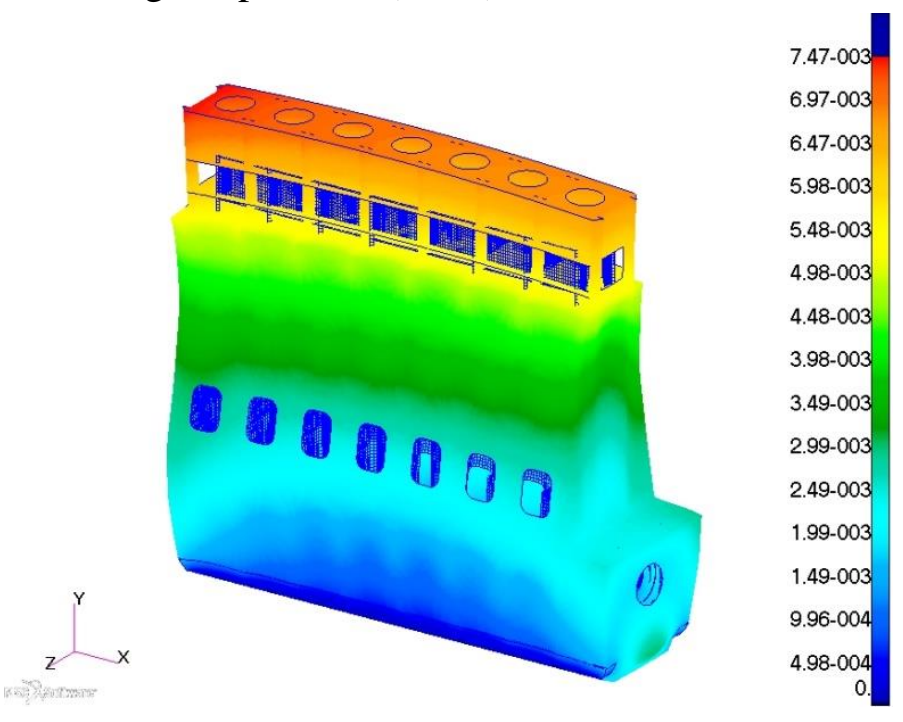

Fig. 10. Engine body deformation under heating influence

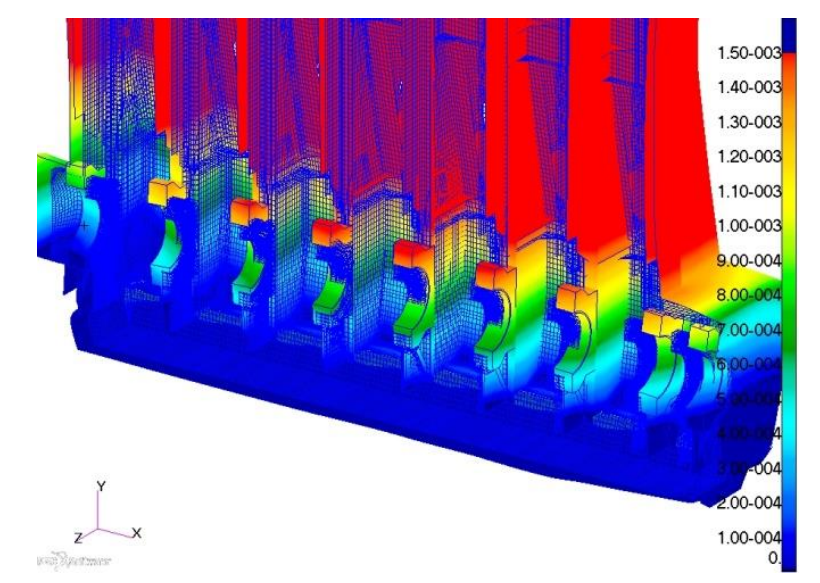

Fig. 11. The main bearings foundation displacement under the heat influence

Table 2 Thermal Displacements of the Main Bearings of MAN B\&W K98MC Engine

\begin{tabular}{|c|c|c|c|}
\hline $\begin{array}{c}\text { Main } \\
\text { Bearing } \\
\text { No. }\end{array}$ & $\begin{array}{c}\text { Vertical Displacement } \\
\text { [mm] }\end{array}$ & $\begin{array}{c}\text { Horizontal } \\
\text { Displacement } \\
\text { [mm] }\end{array}$ & $\begin{array}{c}\text { Axial Displacement } \\
\text { [mm] }\end{array}$ \\
\hline 1 & 0.080 & 0.067 & -1.835 \\
\hline 2 & 0.421 & 0.011 & -1.181 \\
\hline 3 & 0.591 & 0.007 & -0.718 \\
\hline 4 & 0.671 & 0.019 & -0.337 \\
\hline 5 & 0.697 & 0.031 & 0.036 \\
\hline 6 & 0.651 & 0.065 & 0.432 \\
\hline 7 & 0.551 & 0.063 & 0.771 \\
\hline 8 & 0.404 & 0.048 & 1.622 \\
\hline 9 & 0.099 & 0.021 & 1.601 \\
\hline
\end{tabular}




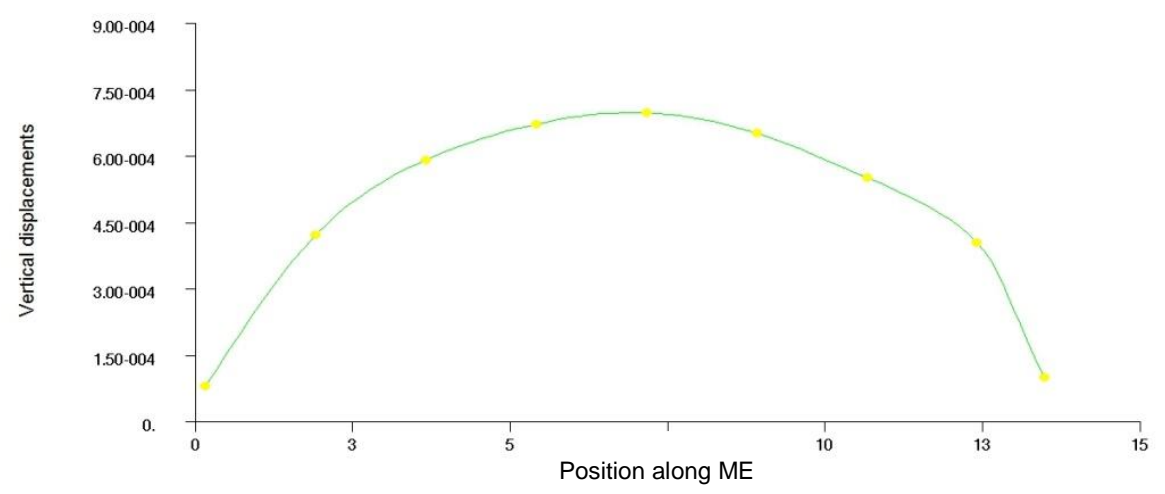

Fig. 12. Diagram of thermal vertical displacement of crankshaft axis

The numerically computed (tab. 2) average value of the translation of the crankshaft's axis $(0.46 \mathrm{~mm})$ is greater than the one recommended by the producer $(0.37 \mathrm{~mm})$. The difference is not particularly big (bellow 20\%), but the displacement is of a hogging type. It seems that the producer's assumption about the parallel translation of the crankshaft's axis is incorrect. The hogging type deformation of the crankshaft results can have significant influence on the moment load coming from the shaft line. The effect seems to be considerable in the precise shaft line alignment analysis. Presented conclusion should be treated with caution because the thermal deformation of ship hull is not taken into account. Heat is flowing from the engine to the ship hull and locally it may be a source of other deformation of engine foundation. An analysis of the temperature deformation of ship hull in the engine room area is planned by the author.

Horizontal deformations of the crankshaft axis under the heating are negligible, in spite of the temperature differences between left and right sides of the engine body. This is in accordance with the marine engines manufacturers' recommendations. They recommend that the shaft line alignment is performed only in vertical plane.

\section{Influence of crankshaft axis thermal deformation on shaft line alignment and crankshaft springing}

Influence of crankshaft axis thermal deformation on shaft line alignment was analysed with usage of author's specialized software $[15,16]$. The software is based on finite element method. The main advantages of the software are: modeling of stern tube bearing as a continuous support and taking into account elasticity of propulsion system foundation. Several calculations were performed for the analysed propulsion system accounting for the analyses of the oil film distribution (non-linear Reynolds equation) in the sliding bearings (especially the stern tube bearing with a variable clearance) [17]. Finally, two models (results) were compared: with crankshaft axis thermal deformation recommended by the engine's producer and the other one determined on the base of the analysis presented in chapter 4. An example of the shaft line alignment analyses (the deformation and the bending moments and shear forces distribution) performed by the author are presented in Fig. 13 and 14. Two values of shaft line deformation (Fig. 13) are important. First one: absolute linear deformation (left axis) given usually in millimeters; and second one: angular deformation - shaft line rotation, given in shipyards practice in millimeters per meters (right axis). Both results have been achieved for the most complicated model with the numerically estimated stiffnesses of the propulsion system [18] and the thermal deformations. 


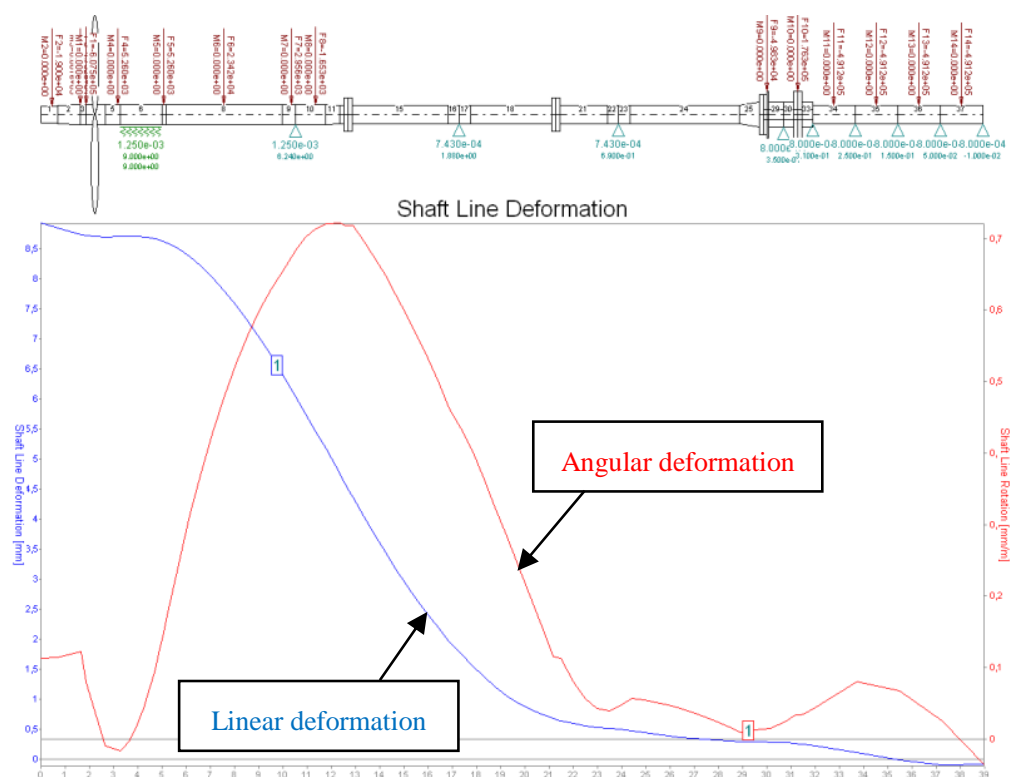

Fig. 13. Shaft line deformation after taking into account the actual thermal deformation of the crankshaft axis

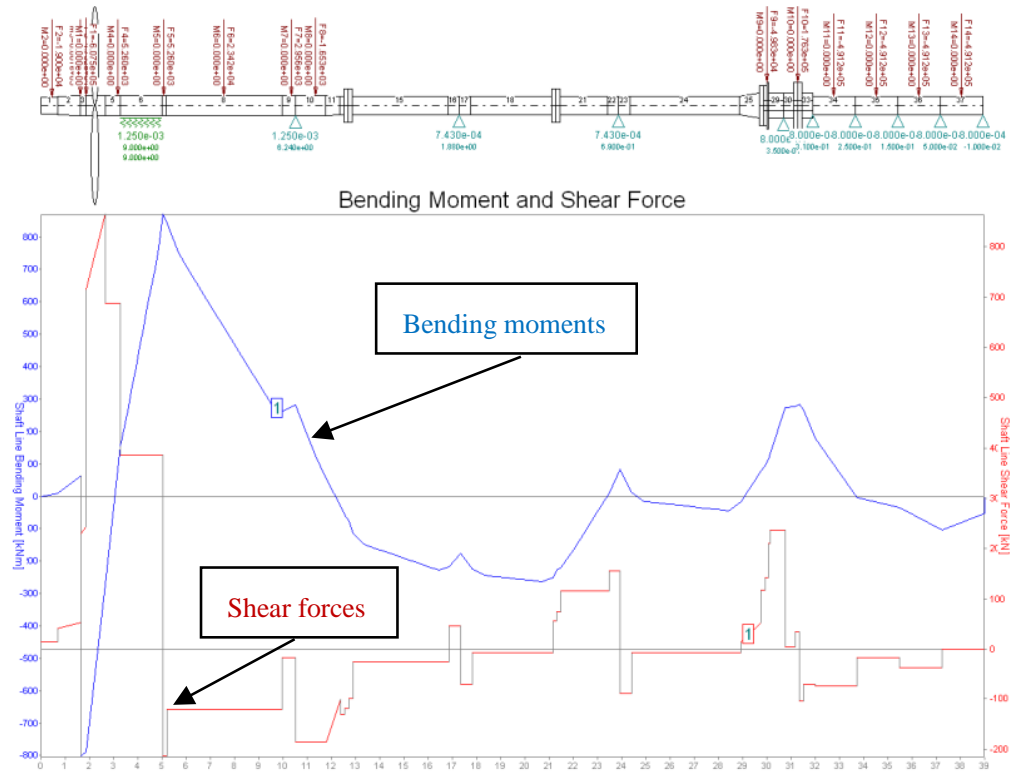

Fig. 14. Shaft line bending moments and shear forces distribution after taking into account the actual thermal deformation of the crankshaft axis

Taking into consideration detailed thermal deformation of crankshaft axis has not big influence on calculation results of global parameters of shaft line alignment. The Fig. 13 and Fig. 14 correspond to the inclusion of the thermal load deformations. The analogous curves for the case of neglecting this deformation look qualitatively similar. The quantitative differences between both cases are as follows. Maximal bending stress was changed by $2.2 \%$. Shaft line bearings' (except the fore intermediate bearing) reactions value was changed less than $9 \%$. But the hogging type of the thermal deformation of the crankshaft axis has big influence on the mutual loading between the crankshaft and the shaft line. The reaction of the fore intermediate bearing (closest to the crankshaft) was changed by $24 \%$ (bearing loading was increased by $64 \mathrm{kN}$ ). Also, loadings of first three main bearings of crankshaft were changed significantly. Main bearing No. 1 was relieved by $173 \mathrm{kN}$ (71\%), No. 2 was more loaded by $27 \mathrm{kN}(10 \%)$ and No. 3 was also more loaded by $96 \mathrm{kN}(23 \%)$. Other main bearings are not sensitive to model changes. Also, bending moment and shear force acting on crankshaft flange was changed significantly. Discussed values of the shaft line alignment are presented in table 3. 
Table 3 The most important influences of the crankshaft thermal displacement on the shaft line alignment parameters

\begin{tabular}{|l|c|c|}
\hline & Cold main engine & Hot main engine \\
\hline $\begin{array}{l}\text { Reaction of the fore } \\
\text { intermediate bearing }\end{array}$ & $271 \mathrm{kN}$ & $331 \mathrm{kN}$ \\
\hline $\begin{array}{l}\text { Reaction of the main } \\
\text { bearing No. 1 }\end{array}$ & $244 \mathrm{kN}$ & $71 \mathrm{kN}$ \\
\hline $\begin{array}{l}\text { Reaction of the main } \\
\text { bearing No. 2 }\end{array}$ & $268 \mathrm{kN}$ & $295 \mathrm{kN}$ \\
\hline $\begin{array}{l}\text { Reaction of the main } \\
\text { bearing No. 3 }\end{array}$ & $421 \mathrm{kN}$ & $517 \mathrm{kN}$ \\
\hline $\begin{array}{l}\text { Bending moment on the } \\
\text { flange of the crankshaft }\end{array}$ & $53.0 \mathrm{kNm}$ & $148 \mathrm{kN}$ \\
\hline $\begin{array}{l}\text { Shear force on the flange } \\
\text { of the crankshaft }\end{array}$ & $134 \mathrm{kN}$ & \\
\hline
\end{tabular}

Influence of crankshaft axis thermal deformation on its springing was analysed with usage of Nastran-Patran software. The crankshaft of eight-cylinder engine was calculated. The analyses were performed for two propulsion system's working conditions: cold (just after shaft line and crankshaft connection) and hot (engine body is thermally deformed after relatively long continuous working). The crankshaft foundation elasticity was taken into account as well as the bending moment and the shear force coming from shaft line. Changes of the distance between the crank arms were calculated for 8 different crankshaft positions ( $45^{\circ}$ increments). The deformed crankshaft in the hot working condition was presented in Fig. 15. Cranks springing values in relation to limits data given by the engine producer - MAN B\&W, for each cylinder in hot condition (with thermal deformation of crankshaft axis) are presented in Fig. 16.
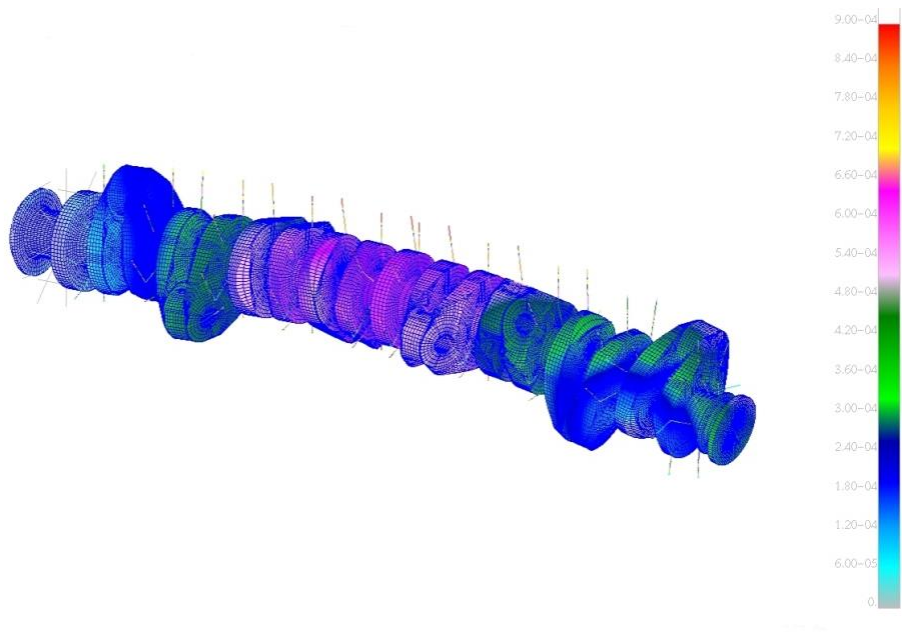

Fig. 15. Crankshaft deformed by thermal displacement of its axis 


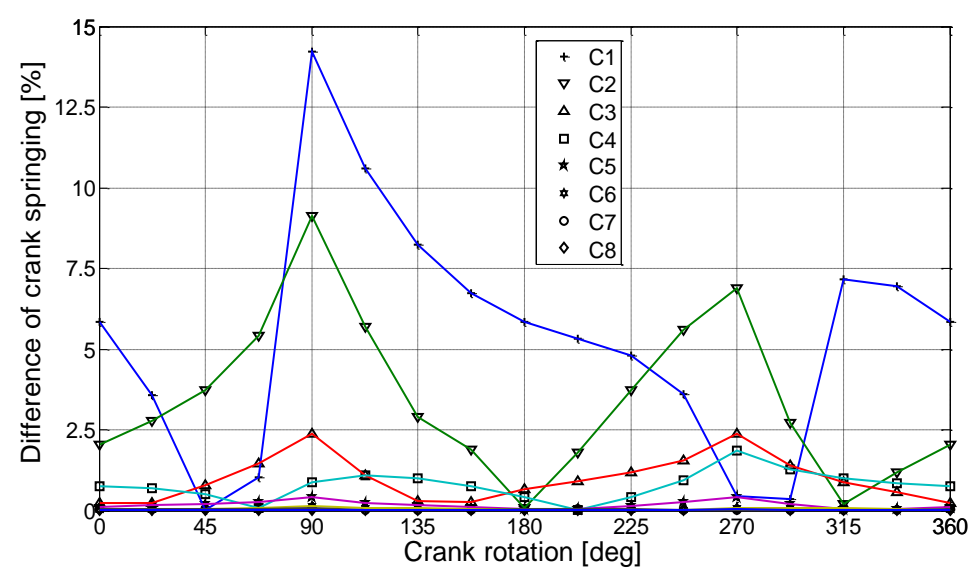

Fig. 16. Relative cranks' springing values in hot condition

The influence of the shaft line on the crankshaft loading (the bending moment and the shear force), just after connection (cold condition) is inconsiderable. The springing difference before and after connection do not exceed $1 \%$ for most cranks. Only for the second and third crank it is greater but still does not exceed 3\%. The thermal deformation of the crankshaft axis has big influence on two first cranks: the change of those cranks springing in relation to the limit values achieved $14 \%$. Influence on the rest of cranks is much smaller - the difference does not exceed $2.5 \%$. It means that the loading values of the first three main bearings may be higher than theoretical.

\section{Conclusions}

The first significant natural modes (eigenvalues) of engine body have natural frequencies above the range of excitation frequencies of the propulsion system. What's more the significant natural modes are quite few and those of interest are of the whole engine's body. It speaks well about the right design - the rigid structure of the engine's body. Therefore, dynamic stiffness of the engine bearings should not be much different to the static stiffness. While the boundary conditions (the modelling method of the ship hull and the engine foundation) have not very important influence on natural frequencies of main bearings foundations, the global engine eigenvalues are completely different. The modelling method of boundary conditions is essential during engine body analyses.

The thermal displacement of the crankshaft computed by numerical analysis is greater than the value recommended by the producer. The difference is not particularly big (bellow $20 \%$ ) but the displacement is hogging type and is a source of the additonal bending moment and shear force acting between the crankshaft and the shaft line. It seems that the producer's assumption about the parallel translation of the crankshaft's axis is incorrect. The effect seems to be considerable for the precise shaft line alignment analysis. Presented conclusion should be treated with caution because the thermal deformation of ship hull is not taken into account. Horizontal deformations of the crankshaft axis under the heating are negligible, in spite of the temperature differences between left and right sides of the engine body.

The detailed thermal deformation of the crankshaft axis has not big influence on calculation results of the global parameters of the shaft line alignment. But the hogging type of the thermal deformation of the crankshaft axis has significant influence on the mutual loading between the crankshaft and the shaft line. Loadings of the intermediate bearing close to the crankshaft as well as loadings of three first engine's main bearings can change significantly. The thermal deformation of crankshaft axis has also big influence on the crankshaft springing 
for two first cranks. It also means that the loading value of the first three main bearings may be higher than theoretical.

This direction of research looks very promising. It may allow improvement in installation of high power propulsion systems and avoiding failure of the engine's main bearings. The worked out methodology may be used for more advanced and complete numerical computations for multiple main engine types together with specific ship's hulls. As a further step, the propulsion system analysis methodology should be elaborated, which incorporates more complex crankshaft representation including in full its 3D characteristics. The effect of crankshaft's springing on the shaft line alignment should also be examined further.

\section{REFERENCES}

[1] Guidance notes on propulsion shafting alignment. American Bureau of Shipping, Houston 2004.

[2] Shafting alignment for direct coupled low-speed diesel propulsion plants. MAN B\&W Diesel A/S, Copenhagen 1995.

[3] Simm A., Qing Wang, Songling Huang, Wei Zhao: Laser based measurement for the monitoring of shaft misalignment, Measurement, Vol. 87, pp. 104-116, 2016. http://dx.doi.org/10.1016/j.measurement.2016.02.034.

[4] Min Churl Songa, Young Hoon Moon: Coupled electromagnetic and thermal analysis of induction heating for the forging of marine crankshafts, Applied Thermal Engineering, Vol. 98, pp. 98-109, 2016. http://dx.doi.org/10.1016/j.applthermaleng.2015.11.129.

[5] Fontea M., Duartea P., Anesb V., Freitasb M., Reisb L.: On the assessment of fatigue life of marine diesel engine crankshafts, Engineering Failure Analysis, Vol. 56, pp. 51-57, 2015. http://dx.doi.org/10.1016/j.engfailanal.2015.04.014.

[6] Yong Yang, Wenyong Tang, Jie Ma: Analysis of shafting alignment for container vessels based on improved transition matrix method, Procedia Engineering, Vol. 15, pp. 5373 - 5377, 2011. http://dx.doi.org/10.1016/j.proeng.2011.08.996.

[7] Rules for classification of ships, Rotating Machinery, Power Transmission, Chapter 4, Part 4. Det Norske Veritas, July 2013.

[8] Sulzer RTA-C. Technology Review. Wartsila, Helsinki 2003.

[9] Bearings. MAN B\&W Diesel A/S, Copenhagen 2000.

[10] Elasto-hydro-dynamic evaluation of main bearing performance. MAN B\&W Diesel A/S, Copenhagen 2002.

[11] Andersen IMV, Jensen J.J.: Measurements in a container ship of wave-induced hull girder stresses in excess of design values. Marine Structures, Vol. 37, pp. 54-85, 2014. http://dx.doi.org/10.1016/j.marstruc.2014.02.006.

[12] Iijima K, Yao T, Moan T.: Structural response of a ship in severe seas considering global hydroelastic vibrations. Marine Structures, Vol. 21, pp. 420-445, 2008. http://dx.doi.org/10.1016/j.marstruc.2008.03.003.

[13] Murawski L., Charchalis A.: Simplified method of torsional vibration calculation of marine power transmission system. Marine Structures Vol. 39, pp 335-349, 2014. http://dx.doi.org/10.1016/j.marstruc.2014.10.004.

[14] Senjanović I., Vladimir N., Tomić M., Hadžić N., Malenica Š.: Some aspects of structural modelling and restoring stiffness in hydroelastic analysis of large container ships, Ships and Offshore Structures, Vol. 9, No. 2, 2014., pp. 199-217. http://dx.doi.org/10.1080/17445302.2012.762728.

[15] Murawski L.: Shaft line alignment analysis taking ship construction flexibility and deformations into consideration. Marine Structures, Vol. 18, pp. 62-84, 2005. http://dx.doi.org/10.1016/j.marstruc.2005.05.002.

[16] Murawski L.: Shaft line whirling vibrations: effects of numerical assumptions on analysis results. Marine

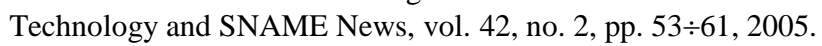

[17] Murawski L.: Static and Dynamic Analyses of Marine Propulsion Systems. Oficyna Wydawnicza Politechniki Warszawskiej, Warszawa 2003, pp. 148.

[18] Murawski L., Szmyt M.: Stifness characteristics and thermal deformations of the frame of high power marine

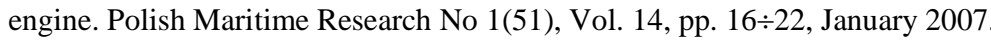

Submitted: $\quad 07.06 .2016$

Accepted: $\quad$ 28.07.2016
Lech Murawski, lemur@wm.am.gdynia.pl

Gdynia Maritime University

ul. Morska 81-87, 81-225 Gdynia, Poland

tel.: +48586901 480, fax: +48586901399 